\title{
ВЫЩЕЛАЧИВАЕМОСТЬ НЕКОТОРЫХ ТЯЖЕЛЫХ МЕТАЛЛОВ иЗ АРГИЛЛИТОВ
}

\author{
(Представил О. Эйзен)
}

В данной работе исследованы аргиллиты, содержащие $15-18 \%$ органического вещества (OB), 4-8\% пирита и значительное количество некоторых редких и рассеянных элементов. Хотя такие аргиллиты и перспективное топливо ['], но в настоящее время из-за малой калорийности еще не нашли использования. Поэтому их, сопутствующих часто и другим полезным ископаемым, просто удаляют в отвалы или смешивают с другими породами. В отвалах происходит их самовозгорание, выделение двуокиси серы при их горении и выщелачивание тяжелых металлов под влиянием атмосферных осадков, часто подкисленных растворенным в них сернистым газом. Возможные процессы при раз-ложении аргиллитов рассмотрены в [ $\left.{ }^{2}\right]$. Там же приведены некоторые данные о выщелачиваемости тяжелых металлов при обработке аргиллитов водой в статических условиях в течение 100 в зависимости от температуры их сжигания.

В настоящей статье приведены данные о выщелачивании аргиллитов в динамических условиях в течение более длительного периода (до 5 месяцев). Учтены и возможность самовозгорания аргиллитов и извлечения тяжелых металлов водой из золы, а также возможность образования и растворения в природных водах двуокиси серы. Эти данные полезны при оценке влияния отдельных факторов на возможное загрязнение окружающей среды вредными тяжелыми металлами в случае скопления аргиллитов в отвалах.

\section{Экспериментальная часть}

Выщелачивание аргиллитов проводили в колонках (диаметр 25 мм, высота фильтрующего слоя $100-140$ cм). Сверху через колонки непрерывным потоком (средняя скорость $0,4-0,5 \mathrm{~m} / \mathrm{Muн}$ ) пропускали дистиллированную воду или раствор двуокиси серы. Температура раствора в течение опыта $15-20^{\circ} \mathrm{C}$. В качестве исходного материала использовали аргиллиты двух месторождений, пробы которых обозначали условно $A$ и $Б$. Проба $A$ характеризуется бо́льшим, чем в пробе $E$, содержанием ОВ и значительно меньшим - пирита и редких металлов (молибдена, ванадия и урана) (таблица). Опыты проводили в четырех колонках. Количество исследуемого материала в каждой колонке составляло 500 2. I и II колонки заполняли золой аргиллита $A$, III золой аргиллита Б. Обжиг обоих аргиллитов был проведен при температуре $800^{\circ}$. IV колонку заполняли натуральным измельченным аргиллитом Б. Колонки I, III и IV промывали дистиллированной водой, колонку II - водным раствором двуокиси серы $(0,001-0,0025$ моль/ $)$. Материал промывали в два этапа: продолжительность главного этапа - 
Результаты выщелачивания элементов из аргиллита и его золы водой и разбавленным водным раствором сернистого газа

\begin{tabular}{|c|c|c|c|c|c|c|c|c|c|c|}
\hline \multirow[b]{3}{*}{ Материал } & \multirow[b]{3}{*}{ Агент } & \multicolumn{3}{|c|}{ Ванадий } & \multicolumn{3}{|c|}{ Молибден } & \multicolumn{3}{|c|}{ Уран } \\
\hline & & \multirow{2}{*}{ 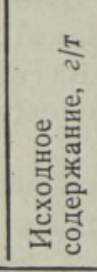 } & \multicolumn{2}{|c|}{$\begin{array}{l}\text { Выщелачен- } \\
\text { ное кол-во }\end{array}$} & \multirow{2}{*}{ 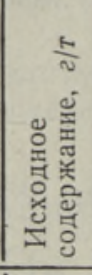 } & \multicolumn{2}{|c|}{$\begin{array}{c}\text { Выщелачен- } \\
\text { ное кол-во } \\
\end{array}$} & \multirow{2}{*}{ 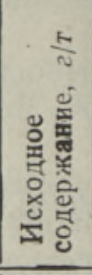 } & \multicolumn{2}{|c|}{$\begin{array}{l}\text { Выщелачен- } \\
\text { ное кол-во }\end{array}$} \\
\hline & & & $\begin{array}{l}0 \\
\text { 乌⿺ँّ } \\
\text { ต் }\end{array}$ & 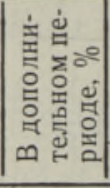 & & 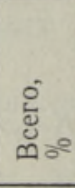 & 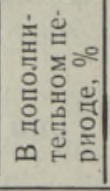 & & 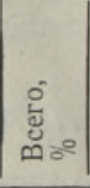 & 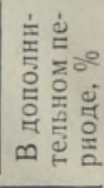 \\
\hline $\begin{array}{l}\text { Зола } \\
\text { аргиллита } A\end{array}$ & $\begin{array}{l}\text { Вода } \\
\text { Раствор } \mathrm{SO}_{2}\end{array}$ & $\begin{array}{l}636,4 \\
636,4\end{array}$ & $\begin{array}{l}39,2 \\
97,5\end{array}$ & $\begin{array}{l}20,1 \\
67,1\end{array}$ & $\begin{array}{l}140,3 \\
140,3\end{array}$ & $\begin{array}{l}35,1 \\
35,5\end{array}$ & $\begin{array}{l}1,5 \\
6,4\end{array}$ & $\begin{array}{l}41,0 \\
41,0\end{array}$ & $\begin{array}{r}1,7 \\
37,9\end{array}$ & $\begin{array}{r}0,63 \\
27,60\end{array}$ \\
\hline $\begin{array}{l}\text { Зола } \\
\text { аргиллита } \quad 5\end{array}$ & Вода & 1092,0 & 33,0 & 22,4 & 536,0 & 31,9 & 0,6 & 182,0 & 0,93 & 0,30 \\
\hline Аргиллит $B$ & Вода & 966,0 & 3,5 & 0,9 & 435,0 & 44,0 & 15,6 & 176,0 & 10,30 & 0,18 \\
\hline
\end{tabular}

30, а дополнительного - 7 сут. В перерыве между этапами (4 месяца) исследуемый материал находился в контакте с промывным. раствором. Количество собранного фильтрата измерялось за определенные промежутки времени (от 1 ч в начале опыта до 4 сут в конце). В пробах, концентрированных при необходимости выпариванием, определяли молибден, ванадий и уран. Содержания молибдена и урана определяли колориметрически: молибден - в форме роданидного комплекса [ $\left.{ }^{3}\right]$, а уран, после его экстракции этилацетатом, - в виде комплекса c АРСЕНАЗО-III [ [4,5]. Количество ванадия определяли титрованием раствором соли Мора [ $\left.{ }^{3}\right]$.

\section{Обсуждение результатов}

Из зол аргиллитов часть молибдена извлекается быстро (рис, 1, 2), и в первых пробах фильтрата достигнута концентрация молибдена 35-50 мг/л. Затем содержание молибдена в фильтрате уменьшается (за весь осталыной период - меньше 0,5 мә/ $\Omega$ ). Извлечение молибдена заметно не возрастает за весь дополнительный период $(1,5 \%)$. Количество извлеченного молибдена из золы не меняется при пропускании через золу водного раствора сернистого газа: в обоих случаях - $35 \%$ (таблица).

Из измельченного натурального аргиллита молибден выщелачивается гораздо медленнее, чем из его золы (рис. 2). Концентрация молибдена в первых пробах фильтрата составляет 11 мг/л, после пропускания $7 \Omega$ воды 7 мг/ $\Omega$, а после $14 \Omega-5$ мг/ $\Omega$; кривая выщелачивания проходит через несколько концентрационных пиков. Общее извлечение молибдена из натурального аргиллита составляет $44 \%$, при этом в дополнительном периоде извлекается $15 \%$ (т. е. в 10 раз больше, чем из золы). Быстрое извлечение молибдена в водный раствор из золы аргиллита, полученной при температуре $800^{\circ}$, отмечено и в [ $\left.{ }^{2}\right]$, где опыты проводились в статических условиях (в течение 7,5 ч 25-30\% молибдена).

Из зол аргиллитов $A$ и $E$ ванадий выщелачивается значительно медленнее молибдена (максимально 25-30 мح/л ванадия в фильтрате). Общее извлечение ванадия из зол обоих типов аргиллитов составляет $33-39 \%$, при этом за дополнительный период - 20-22\%. Применение водного раствора сернистого газа для выщелачивания золы аргил- 

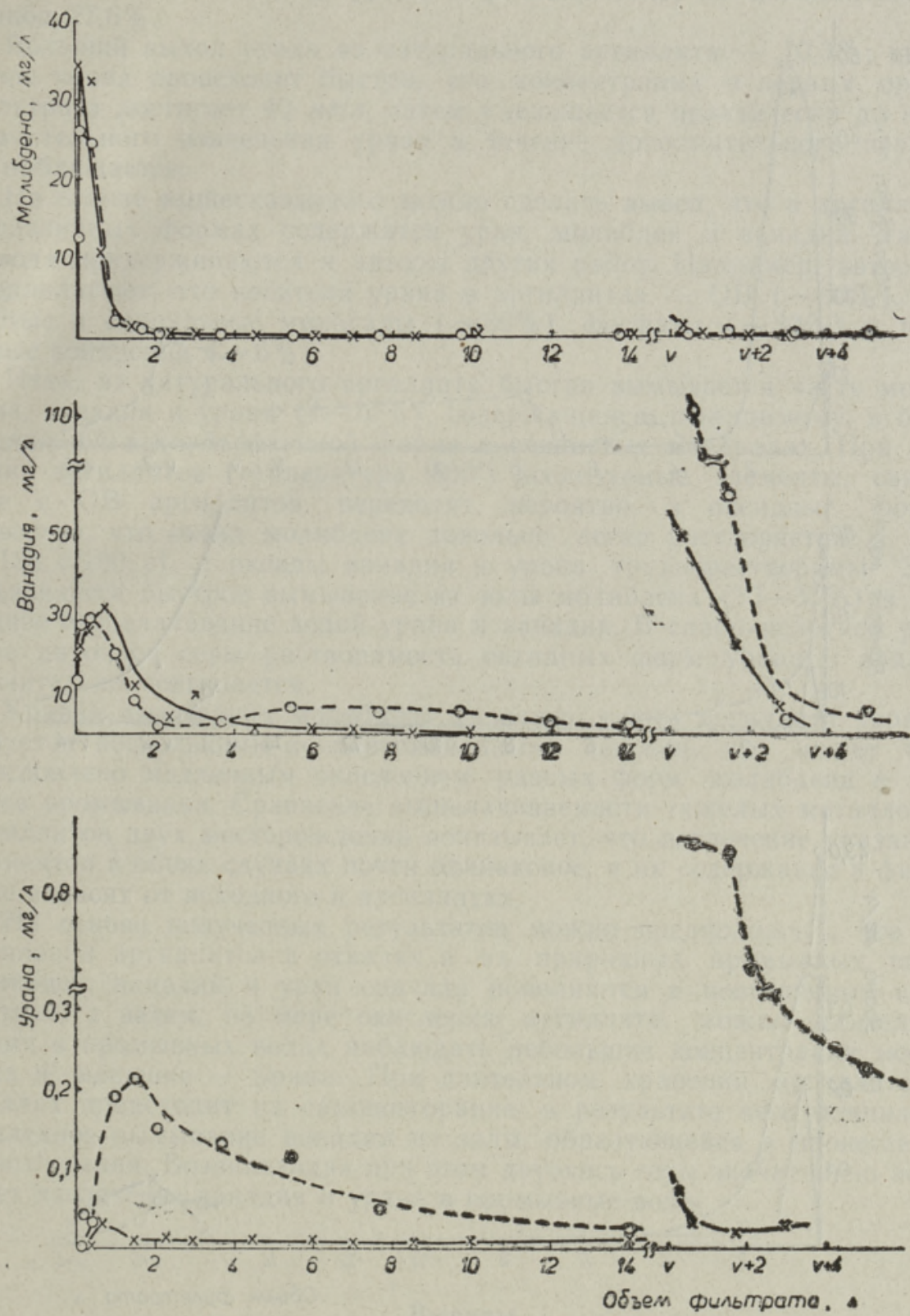

Рис. 1. Выходные кривые выщелачивания молибдена, ванадия и урана из золы аргиллита $A ; x$ - реагент - вода; 0 - реагент - водный раствор $\mathrm{SO}_{2}$.

лита заметно повышает выход ванадия (в основном периоде $30 \%$, в дополнительном до $67,1 \%$ при общем извлечении ванадия до 95\%); максимальное содержание ванадия в фильтрате увеличивается до $110 \mathrm{ma} / \Omega$.

Иначе выглядит кривая выщелачивания ванадия из натурального аргиллита (рис. 2). Концентрация ванадия в фильтрате быстро растет, достигая в первых пробах 50 мг/ $\Omega$, но после пропускания $1,5 \Omega$ воды падает уже до нуля. Извлечение ванадия не повышается и в течение дополнительного периода; общее извлечение его из натурального аргил- 

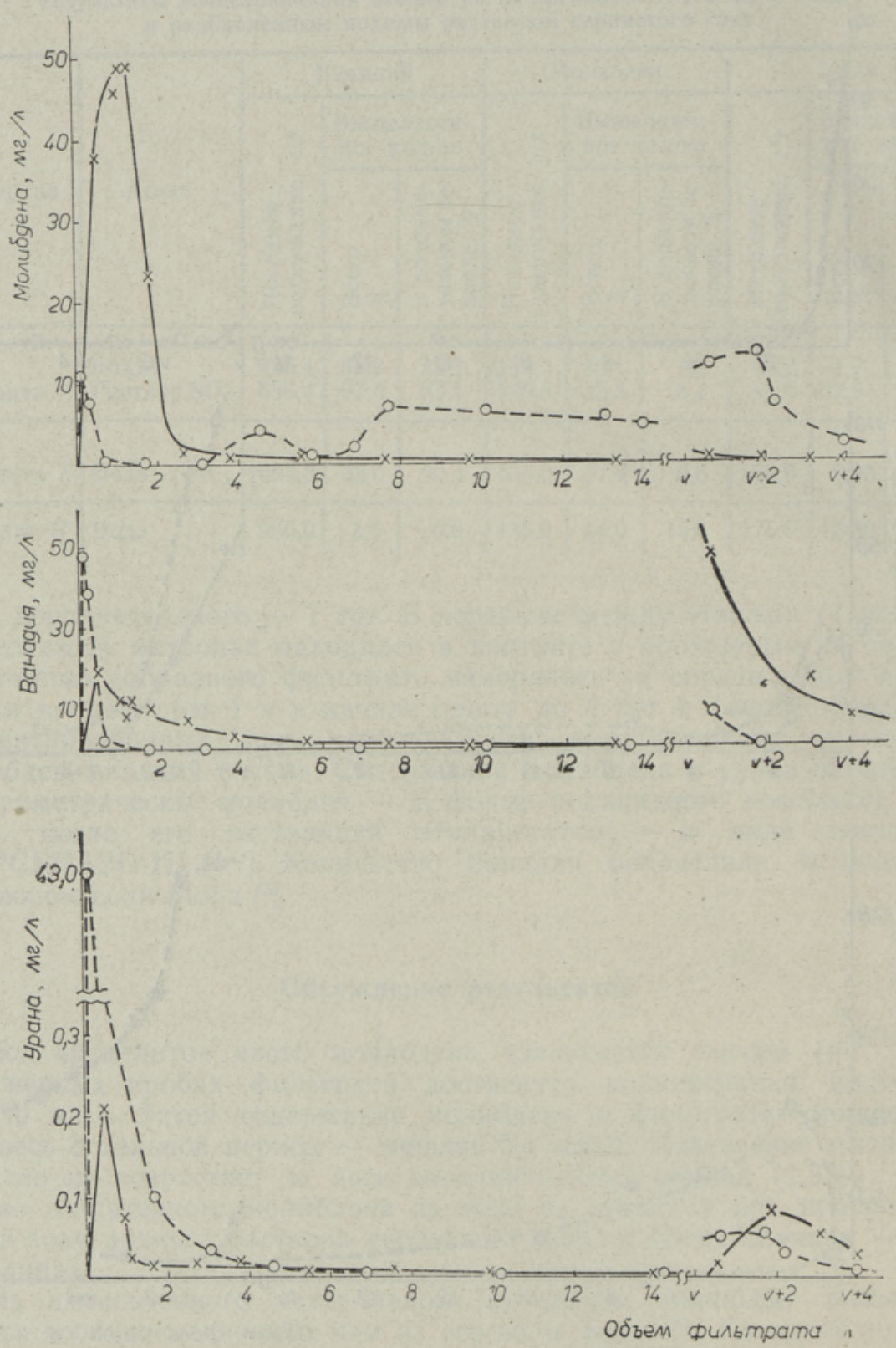

Рис. 2. Выходные кривые выщелачивания молибдена, ванадия и урана водой из аргиллита $5(o)$ и из его золы $(x)$.

лита лишь $3,5 \%$. В статических условиях [2] в течение 100 ч из золы аргиллита извлекали $10 \%$ ванадия.

Медленно выщелачивается и уран из золы аргиллита. В первых пробах фильтрата концентрация урана достигает 0,2 мг/л, затем она падает и стабилизуется при значении $0,01-0,02$ мг/л. Выход урана значительно повышается в течение дополнительного периода, но общее извлечение лишь $1-2 \%$, причем одна треть этого количества урана извлекается в течение дополнительного периода. При использовании водного раствора сернистого газа выход урана существенно увеличи- 
вается: общее извлечение урана в раствор $38 \%$, за дополнительный период $27,6 \%$.

Бо́льший выход урана из натурального аргиллита - 10,3\%; вымывание урана происходит быстро, его концентрация в первых пробах фильтрата достигает 40 мг/ $\Omega$, затем уменьшается практически до нуля. Значительного извлечения урана в течение дополнительного периода не наблюдается.

На основе вышесказанного можно сделать вывод, что в аргиллитах в различных формах содержатся уран, молибден и ванадий. Такого вывода придерживаются и авторы других работ. Например, авторы [6] предполагают, что носители урана в аргиллитах - OB $(\sim 30 \%)$, глинистые и силикатные минералы $(\sim 30 \%)$, фосфаты $(\sim 30 \%)$ и пиритовые конкреции $(\sim 6 \%)$.

Итак, из натурального аргиллита быстро вымывается часть молибдена, ванадия и урана $(4-10 \%)$, содержащаяся, по-видимому, в более подвижной адсорбированной форме в глинистых минералах. При сжигании аргиллитов (температура $800^{\circ}$ ) исследуемые элементы, связанные с ОВ аргиллитов, переходят, вероятно, в оксидные формы. Известно, что оксид молибдена довольно легко растворяется в воде $(0,138$ г/100 г), а оксиды ванадия и урана труднорастворимы. Этим объясняется быстрое вымывание из золы молибдена $(30-35 \%)$ и медленнсе выщелачивание водой урана и ванадия. В слабокислотном растворе́ двуокиси серы растворимость оксидных форм урана и ванадия значительно повышается.

Кривая вымывания молибдена из натурального аргиллита характеризуется несколькими концентрационными пиками, что может быть обусловлено медленным окислением разных форм молибдена в процессе промывания. Сравнение выщелачиваемости тяжелых металлов из аргиллитов двух месторождений показывает, что извлечение указанных элементов в обоих случаях почти одинаковое, и их содержание в фильтрате зависит от исходного в аргиллитах.

На основе полученных результатов можно предположить, что при скоплении аргиллитов в отвалах в их природных промывных водах молибден, ванадий и уран сначала появляются в повышенных количествах, а затем, по мере окисления аргиллита, можно длительное время в промывных водах наблюдать небольшие концентрации молибдена и меньшие - урана. При длительном хранении аргиллитов в отвалах происходит их самовозгорание, в результате чего начинается медленное вымывание ванадия из золы, образующейся в процессе самовозгорания. Возникающая при этом двуокись серы значительно повышает извлечение ванадия и урана в промывные воды.

\section{Выводы}

1. Аргиллиты могут быть серьезным источником загрязнения окружающей среды, т.к. атмосферные осадки вымывают из них тяжелые металлы в течение длительного периода.

2. Факторы горения аргиллитов и присутствие двуокиси серы в атмосферных осадках существенно влияют на процесс вымывания тяжелых металлов.

3. Нужно иметь в виду, что приведенные здесь результаты показывают лишь зависимость выщелачивания тяжелых металлов из аргиллитов от некоторых факторов (времени, горения, присутствия двуокиси серы) и не охватывают комплекса сложных и многосторонних природных процессов. 
1. Kivimägi, E. Eesti senikasutamata maavara. - Eesti Loodus, № 4, lk. 199-202.

2. Альтгаузен М., М аремяэ Э., Иоханнес Э., Липпма а Э. Гипергенное разложение черных металлоносных сланцев. - Изв. АН ЭССР. Хим., 1980, т. 29 , № 3, с. $165-169$.

3. Б усев А. И., Т и п цо в а В.Г., Ив ан $\sigma$ в В. М. Руководство по аналитической химии редких элементов. М., 1978, с. 175, 236.

4. Morrison, G. H., Freiser, H. Solvent Extraction in Analytical Chemistry. N. Y., 1957 , p. 242.

5. Лукьянов В. Ф., Саввин С. Б., Никольская И. В. Фотометрическое определение микроколичеств урана с реагентом АРСЕНАЗО-III. - ЖАХ, 1960, т. 15 , № 3, с. 311 .

6. Гецева Р. В., Дерягин А. А., Созинов П. А., Сидоренко С. А. Геологичесқие особенности и ураноносность формаций черных сланцев. М., 1981.
Институт химии
Академии наук Эстонской ССР
Поступила в редакцию
7/XII 1981

\section{R. PALVADRE, Tiia KLEEMEIER}

\section{MÓNINGATE RASKEMETALLIDE LEOSTUMINE ARGILLIITIDEST}

On toodud andmed molübdeeni, vanaadiumi ja uraani leostumise kohta argilliitidest vee toimel pikaajalistes dünaamilistes katsetes. Nimetatud elemente eraldus vesilahusesse $10-45 \%$ ulatuses, kusjuures leostumine sōltus oluliselt protsessi kestusest, argilliitide tuhastamisest ja vääveldioksiidi sisaldusest leostuslahustes. Saadud andmed lubavad teha järeldusi mōningate faktorite môju kohta raskemetallide leostumisele argilliitidest aherainemägedes.

\section{R. PALVADRE, Tiia KLEEMEIER}

\section{LEACHING OF SEVERAL HEAVY METALS FROM ARGILLITES}

The leaching process of $\mathrm{Mo}, \mathrm{V}$ and $\mathrm{U}$ with water from argillites under conditions of a continuous dynamic laboratory experiment is discussed. The yield of these metals from argillites reaches up to $10-45 \%$ and depends greatly on the time factor, thermal decomposition of argillites before leaching, and the presence of $\mathrm{SO}_{2}$ in leaching water. The experiment results permit to draw conclusions about the importance of the above factors in the leachability of heavy metals from argillites contained in waste dumps. 